\title{
High-pressure experimental models of geological structures
}

\author{
G.D. Couples ${ }^{1, \mathrm{a}}$ and H. Lewis ${ }^{1}$ \\ ${ }^{1}$ Institute of Petroleum Engineering, Heriot-Watt University, Edinburgh EH14 4AS, Scotland
}

\begin{abstract}
In order to understand deformation processes that operated in large-scale, natural systems, experimental models can provide a crucial means of developing ideas concerning the interactions of sub-systems. We describe an experimental campaign that was designed to provide new insights into a multi-scale deformation type that involves faulting, uplift and rotation of strong crustal blocks, and the folding of the overlying sequence of layered rocks. The experimental models proved, at a small scale, the existence of a process that could only be inferred at natural scale - namely, the significant lateral flow of a ductile unit that transports the overlying rocks in a nearly passive fashion.
\end{abstract}

\section{Introduction}

Experimental models have long been employed within the geosciences to gain insights into the deformation processes that operated during the development of large-scale subsurface structures. By making appropriate selections of material properties and experimental conditions, it is possible to design models that are fully scaled so that the material strengths and resulting stresses are proportional between the model and reality. In other types of experimental models of geological structures, precise scaling is not attempted, allowing the use of sets of materials whose behaviours and interactions are perhaps even more instructive than is the case in carefully-scaled models. This paper is concerned with models of the latter (un-scaled) type, which use real rock materials to create complex configurations in systems that are deformed under high confining pressure to replicate key processes that are believed to occur in natural deformations [1-6]. The primary reason for choosing to design experiments composed of pieces of rock is that such models can capture the effects of frictional discontinuities, which we believe to be of fundamental importance in the natural deformations that create subsurface structures.

Real geology in the upper crust is typically characterised by rock sequences composed of multiple rock types that are arranged in well-ordered successions of parallel layers (before major deformation occurs) lying above an un-layered basement. During tectonism, the parallel layers of the younger rocks become folded or faulted in local regions that are part of a larger deformation process. Un-scaled experimental models (hereafter called "rock models") have been developed to investigate such folding and faulting processes, aiming to identify the role of layer interfaces in terms of how they govern the resulting shapes and the distributions of concentrated strains. By operating the rock models at high confining pressures (nominally, $50 \mathrm{MPa}$ ), it is possible to choose materials from a range of rock types to assemble layered packages that are composed of rocks with contrasting

\footnotetext{
a e-mail : gary.couples@pet.hw.ac.uk
} 
strengths and appropriate relative ductilities. The practical constraints imposed by operating within a pressure cell mean that such models are necessarily small (perhaps $200 \mathrm{~mm}$ in length, and maybe $40 \mathrm{~mm}$ in height), with the associated difficulties of machining small rock components to high precision. In the models described here, we also make use of non-rock materials, including an assembly of steel blocks, and lead sheets, with each material being chosen because its behaviour under the experimental conditions is appropriate relative to a particular prototype feature. The advantage of using rock materials is the ability to observe and map (via post-experiment thin sections) the precise positions, intensities and characters of the emergent deformation modes. Using knowledge gained from standard testing of these rock materials, we can interpret a spatiallyorganised (and sequential) pattern of mechanical states from which we can re-construct the deformation process and deduce the role of interactions that occur between the components. Such a process model allows us to better interpret large-scale natural deformations and to make predictions about the distributions of altered material properties (such as flow characteristics).

\section{Prototype from nature}

The natural prototype features that inspired the modelling efforts described in this paper occur widely around the world, but they are particularly well expressed in the Rocky Mountains of Wyoming, USA. In mountain ranges that border the adjacent basins, outcrop analogues can be seen that provide a chance to examine the shapes and consider the processes that operated during the development of oilfield-scale structures [7]. A much-studied example is Rattlesnake Mountain (RM), located near Cody, Wyoming (Figure 1). The pre-deformation setting at RM consisted of a rock succession that, from the bottom, reveals old crystalline rocks (the "basement") whose eroded top surface was then covered during a long period of deposition that left behind some $3 \mathrm{~km}$ of layered rocks. The layered rocks can be conveniently divided into three major groups, based on their response to the deformation. At the base (above the basement) is the so-called Cambrian shales ( 400m thick) which can behave in a very ductile fashion, then the Paleozoic carbonates $(\sim 800 \mathrm{~m}$ thick) which act like a stiff beam, and finally the Mesozoic clastics ( $2+\mathrm{km}$ thick) which appear to have intermediate characteristics. About 60 million years ago, the regional planarity of a large part of western North America was markedly altered in a event called the Laramide orogeny, with the basement rocks broken by crustal-scale faults that led to major vertical movements $(+/-10 \mathrm{~km})$ and rigid-body rotations. The younger layered rocks were affected by the movements of the underlying basement during this tectonic episode, resulting in the creation of large folds and/or faults. RM allows an examination of one of these large structural features and provides the chance to develop interpretations concerning the deformation processes that were active.

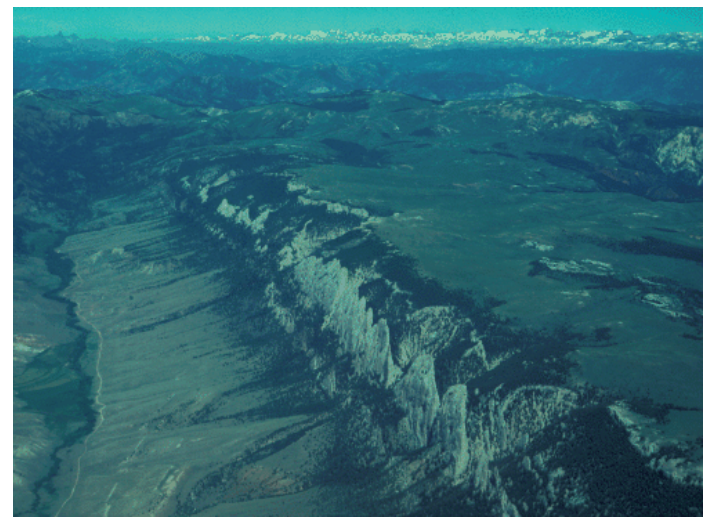

Fig. 1. Image of part of Rattlesnake Mountain. Light-coloured rocks are the Paleozoic carbonate sequence. Note the vertical orientation caused by the folding, 
Clearly, the deformation at RM (and elsewhere) can be best described as comprising a system. In other words, it is possible to interpret the whole process as being composed of major events that control subsequent events, which themselves govern others, etc. A practical starting point is to consider the deformation of the basement rocks, which is the largest observable component of the system. These old rocks continued to mid-crustal depths $(\sim 30 \mathrm{~km})$ as a coherent entity prior to the Laramide orogeny - in other words, they formed the upper crust of the Earth. The observed Laramide-age translations and rotations of the rigid basement blocks, accommodated by very localised shears at the block margins, is sensibly described in the language of brittle deformations. In order to interpret a possible cause for the basement tectonism, it is useful to employ the notion of elastic-until-failure that is often associated with brittle processes. A simple elastic solution (in 2D) suggests that the observed local movements of the basement rocks can be explained as being part of a basin-scale system that was responding to long-wavelength disturbances at depth (Figure 2).
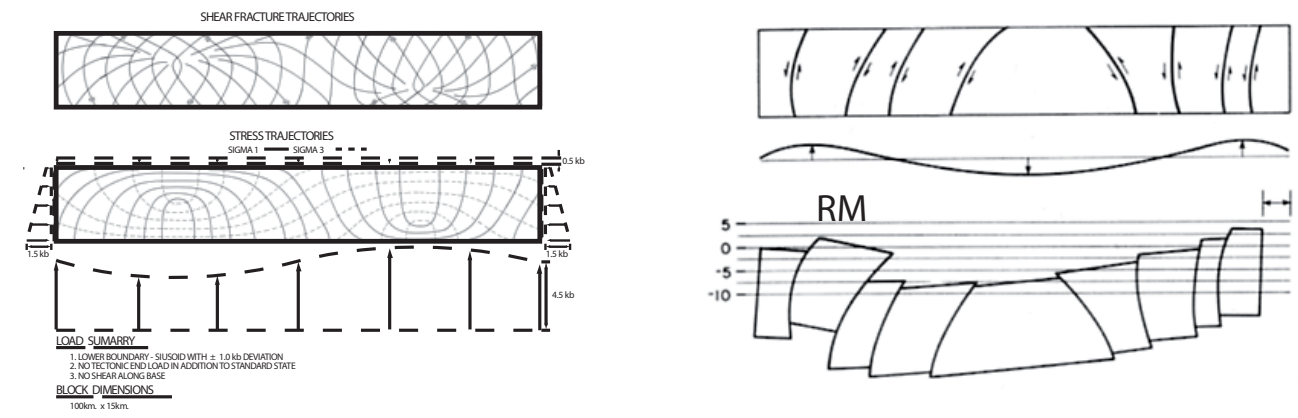

Fig. 2. Explanation for basement tectonics at basin scale, derived from [8, 9]. Left images represent the outcome of a 2D analytical solution for an elastic thick beam, with the loads as indicated. Right images show an interpretation of how some potential fault shapes, derived from elastic solution, could result in a basin shape like that observed for the Big Horn Basin of Wyoming. Rattlesnake Mountain (RM) is associated with a rotated and uplifted block of basement.

Although the layered rock sequence above the basement is very thick from a human perspective, its total thickness $(\sim 3 \mathrm{~km})$ is rather small compared to the scale of the interpreted basement tectonic system. The difference in length-scale, and the specific observations that relate to how the layered rocks responded to the basement motions, both support a hypothesis in which the deformation of the layered rocks is interpreted as a response to the imposed displacements of the basement. That concept underlies the experimental studies described later in this paper. But first, it is useful to outline some of the main observational characteristics of the deformed layered rocks that must be acknowledged when developing a mechanical interpretation for the process that led to the folds that we can see.

At RM (and elsewhere in the region), the carbonate rock sequence is seen in spectacular outcrops with excellent exposure. It is easy to demonstrate that the carbonate rock sequence maintains a uniform thickness throughout the fold, leading to a geometric difficulty (Figure 3). Meanwhile, the Cambrian rocks exhibit major thickness variations in the immediate locale of the folding. The Mesozoic rocks also reveal significant local thickness changes and other features, but these characteristics will not be addressed specifically in this short paper. Together, these descriptions lead to an hypothesis which states that the layered rocks undergo self-actuated motions parallel to the basement/layer contact as a consequence of conditions developed during the folding, and localised to the fold itself. That concept establishes the experimental programme described below. 


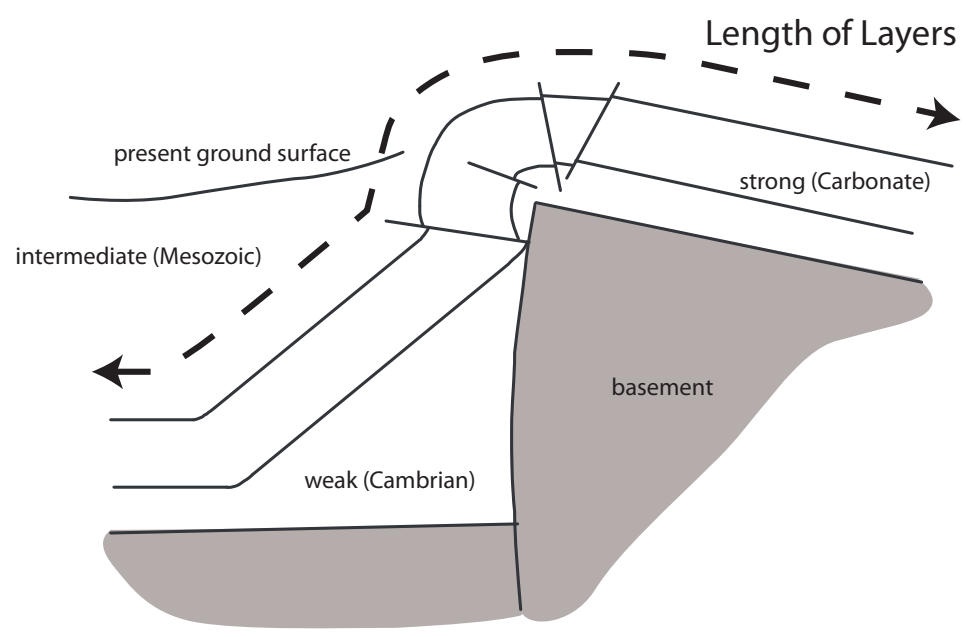

Fig. 3. Simplified vertical cross section illustrating key geometric characteristics of RM. Note the dashed line, which indicates the present-day length of the Carbonate layer. That length is much longer than the comparable length measured at the top of the basement. The vertical offset of the basement top is about $2 \mathrm{~km}$.

\section{Experimental design}

The design of the experimental programme acknowledges the existence of a system comprising numerous parts, their behaviours, and the way that the parts are loaded. In concept, the design includes: (1) an assembly of steel blocks whose motions, during the experiment, mimic those of the basement in the prototype; (2) a package of layers, with the individual layers intended to represent the relevant rock sequence in the prototype; and (3) methods for quantifying displacements (hence allowing strains to be calculated) and stresses. The measurements are mainly derived from postexperiment examination, so a series of initially identical models is operated to varying end states, allowing a reconstruction of the progressive deformation processes that cannot be directly observed.

The experimental apparatus consists of a cylindrical pressure vessel and axial pistons, along with a loading frame. A model is placed into the pressure vessel and surrounded by a plastic jacket, allowing an oil confining fluid to apply a uniform pressure of $50 \mathrm{MPa}$. A piston applies an axial displacement (a compensating piston is used to simplify the maintenance of a constant confining pressure), and the measured force and displacement of the piston provides a record of the overall response of the model.

Each model consists of several components. An assembly of steel blocks, whose mating surfaces are the arcs of cylinders, operates so as to represent the "basement". The arc centres are offset, so a displacement along the length of the assembly induces, under conditions of high confining pressure, rotations and relative displacements on the pre-cut and lubricated arcs. In the centre of the assembly, the motions of the steel blocks produce an uplifted, rotated block that is similar to the configuration of RM (Figure 4). This is the region that will be described later under "Results". The displacement on this arc is used to scale the dimensions of the model components so that the final stage of the model's response is comparable (scaled) to that at RM. The layer of dolostone, which represents a rock succession nearly $1 \mathrm{~km}$ thick, is only $1.55 \mathrm{~mm}$ thick, so the scale factor is between $10^{5}$ and $10^{6}$. The model components are machined from larger pieces of rock by cutting with a rock saw and then using a surface grinder to achieve the final size. The dimensional tolerances are about $0.001 \mathrm{~mm}$. 

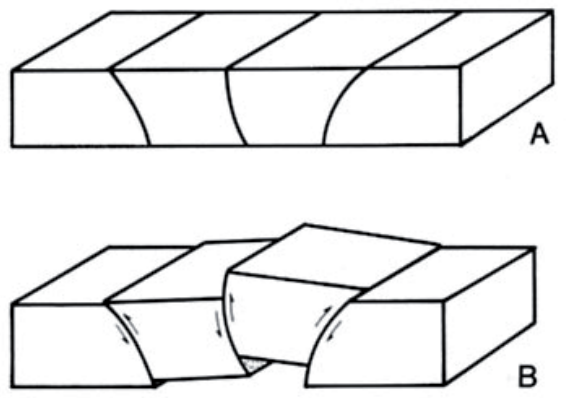

Fig. 4. Design of steel block assembly [5] that converts the axial displacement into rotations and translations of individual blocks.

On one side of the steel blocks (here called "above"), a package of layers represents the Cambrian/Carbonate/Mesozoic rock sequence from the prototype. "Below" the steel blocks, another, less-complex package of layers is present (to avoid eccentric responses); that lower package is not discussed here. In the experiments described in this paper, the upper package consists of lead $(\mathrm{Pb}$, as used on roofs) next to the steel, then a layer of dolostone, and then a layer of porous limestone. Under the $50 \mathrm{MPa}$ confining pressure, the lead behaves in a very ductile fashion, the dolostone as a brittle material, and the limestone as a material with intermediate ductility. All layer interfaces are lubricated. The layers are deliberately shorter than the steel block assembly, so they do not touch the pistons (plasticene, which is extremely ductile under the experimental conditions, fills the gap between the layers and the piston).

The space inside the pressure vessel allows the model system to undergo movements that are comparable (in scaled terms) to those that occurred in the prototype (Figure 5). Because the model system is not cylindrical, but is instead rectilinear, there is a need to protect the plastic jacket from the potential to be punctured by sharp corners. Additional layers of lead sheet are placed around the entire model to serve this purpose. The lead sheets on the "faces" of the model are scribed with a regular grid prior to deformation. The distortion of the grid records the relative movements of the model's parts during the experiment.

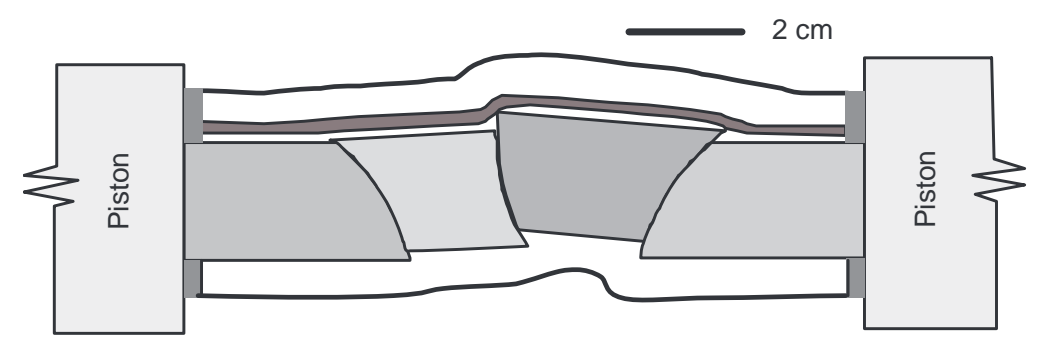

Fig. 5. Sketch of model configuration after loading, showing steel block assembly, adjacent layered packages, ends of pistons, and plasticene plugs between layers and pistons. Not shown: lead sheets around model, plastic jacket for confining pressure.

Following the series of experiments, individual models were examined in detail, and all observable features were recorded. Each of the layered packages (after separation from the steel blocks) was impregnated with epoxy resin, then sliced along the medial plane (parallel to the long dimension). Thin sections (microscope slides) were obtained for each layered package, allowing additional information to be extracted (such as identification of strain domains, local deformation mechanisms, maps of internal stress). The displacement data from the lead jackets was analysed and 
compiled, thus defining a deformation history without any artefacts associated with model disassembly and the inevitable distortions and alterations associated with post-experiment examination.

\section{Results}

The models from this series reveal a clear sequence of deformation that is remarkably similar to the one inferred from studies of natural prototypes. As the rigid block of steel initially lifts up and starts to rotate, the layered package deforms into a subtle fold. Surprisingly, the layers initially move away from the uplift (Figure 6). That movement pattern is soon altered, and the layers then translate towards the uplift (as would be expected from the line-length comparison noted above). As the fold develops, the dolostone and limestone layers acquire arrays of open fractures and shear surfaces (Figure 7). These visible manifestations of strain, and grain-scale observations using thin sections, are manifestations of a stress pattern which indicates that the layered package acts like a thick beam undergoing bending.

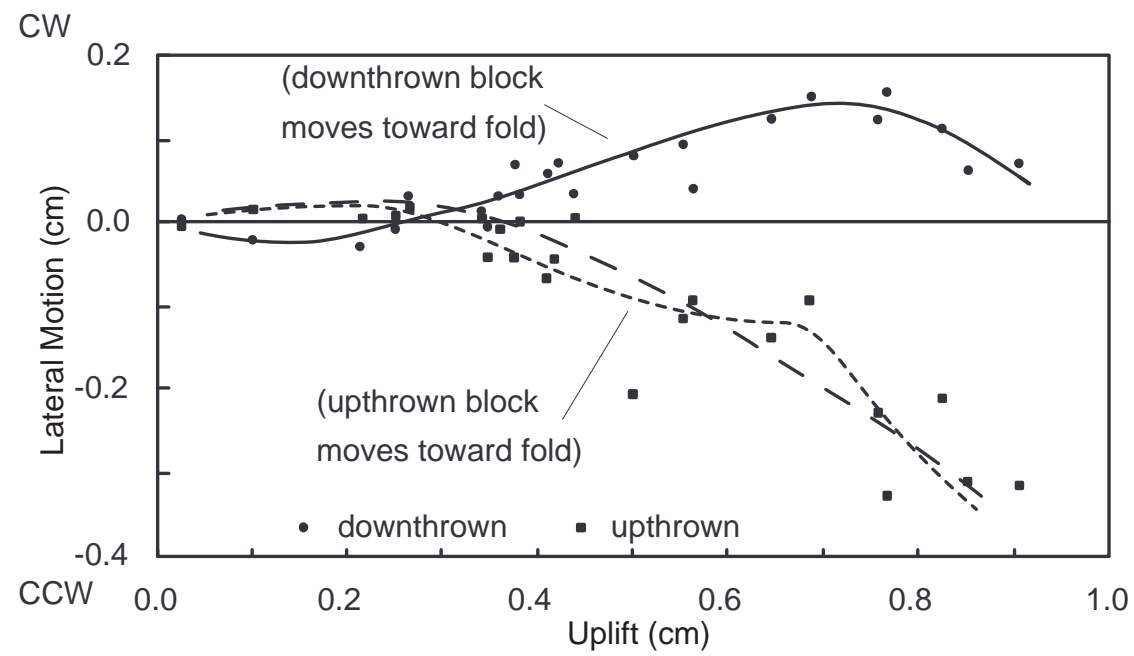

Fig. 6. Plot of measured translations derived from analysis of distorted grids [10]. CW and CCW mean clockwise and counter-clockwise, respectively, to indicate the sense of simple shear along the steel-lead interface. Dashed line indicates an alternate interpretation of the path that is based on the observed movement of the upthrown layers across the fold.

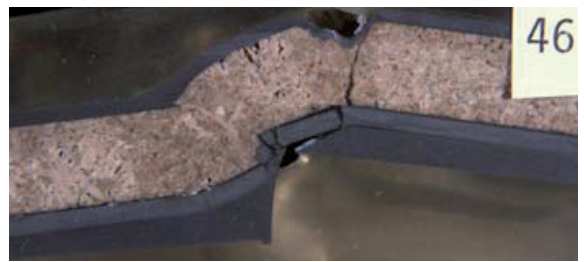

Fig. 7. Image of one deformed model after preservation in epoxy resin and slicing along the medial plane. The steel blocks have been removed. The lowest layer is the lead. The next layer is the dolostone (note the occurrence of multiple fractures). The light layer is the limestone, which exhibits an array of deformation features. The uppermost layer is the protective lead sheet. Dolostone layer is $1.55 \mathrm{~mm}$ thick.

While the dolostone and limestone layers progressively fold, the lead layer is playing a crucial role. Displacement records show that the lead and rock layers all translate towards the fold. In the immediate vicinity of the fold, the lead flows from the uplifted region towards the down-thrown 
block, causing the lead to thicken markedly here. Towards the maximum uplift achieved in the experiments, the dolostone layer touches the face of the steel block (Figure 7), cutting off the flow of lead from the uplifted region. After the lead's path is disrupted in this fashion, the lead on the uplifted block then continues to flow, translating the layers on the upper block across the upturned limb of the fold. Meanwhile, the lead on the downthrown block flows into the region under the dolostone layer, but the flow is apparently insufficient, and the dolostone layer rapidly collapses into that area and flexes into its final shape, acquiring additional fractures as it does so.

\section{Interpretation}

The experimental models provide a rich set of observations and measurements that enable us to create a process-based explanation for the deformation of this partially-scaled system of layers. The movements of the steel blocks impose a set of displacement boundary conditions onto the base of the layered package. The ductile layer at the base of the package plays a major role. It develops regions of high and low pressure (mean stress) on the upthrown and downthrown blocks. The lateral flow of the ductile layer, driven by the gradient, transports the overlying layers. The folding of the dolostone and limestone layers is largely a passive bending, with the ductile bottom layer serving to transform the discrete discontinuity of the steel blocks into a continuous flexure in the stiffer layers above.

Although the experimental models described here are significantly simplified from the complexity of the natural prototype, the models reproduce the main deformation processes that have been deduced from evidence and reasoning derived from studies of outcrops. A major benefit of using such models is that a whole system can be studied, including the sequence of events. In geology, scientists are only able to see the end-points of deformations, and cannot observe the progressive processes directly. Physical models using rock materials can provide important underpinning knowledge that aids our understanding of nature.

\section{References}

1. Handin, J., Friedman, M., Logan, J.M., Pattison, L.J. \& Swolfs, H.S. 1972. Experimental folding of rocks under confining pressure: Buckling of single-layer rock beams. American Geophysical Union Monograph 16, 1-28.

2. Handin, J.W., Friedman, M., Min, K.D., and Pattison, L.J., 1976, Experimental folding of rocks under confining pressure: Part II. Buckling of multilayered rock beams. Geological Society of America Bulletin, 87, 1035-1048.

3. Friedman, M., Handin, J., Logan, J.M., Min, K.D. \& Stearns, D.W. 1976a. Experimental folding of rocks under confining pressure: Part III. Faulted drape folds in multilithologic layered specimens. Geological Society of America Bulletin, 87, 1049-1066.

4. Friedman, M., Hugman, R.H.H. \& Handin, J. 1980. Experimental folding of rocks under confining pressure, Part VIII -- Forced folding of unconsolidated sand and of lubricated layers of limestone and sandstone. Geological Society of America Bulletin, 91, 307-312.

5. Weinberg, D.M. 1979. Experimental folding of rocks under confining pressure, Part VII -Partially scaled models of drape folds. Tectonophysics, 54, 1-24.

6. Couples, G.D., Stearns, D.W. \& Handin, J.W. 1994. Kinematics of experimental forced folds and their relevance to cross-section balancing. Tectonophysics, 233, 193-213.

7. Stearns, D.W. 1978. Faulting and forced folding in the Rocky Mountains foreland. In: Matthews, V. (ed.), Laramide folding associated with basement block faulting in the western United States. Geological Society of America Memoir 151, 1-37.

8. Hafner, W., 1951, Stress distribution and faulting. Geological Society of America Bulletin, 62, 373-398.

9. Couples, G.D. 1977. Stress and shear fracture (fault) trajectories resulting from a suite of complicated boundary conditions with applications to the Wind River Mountains. Pure and Applied Geophysics, 115, 113-133. 
EPJ Web of Conferences

10. Couples, G.D. \& Lewis, H. 1998. Lateral variations of strain in experimental forced folds, Tectonophysics, 295 79-91. 